\title{
Danksagung für die deutsche Ausgabe
}

Das Werk, das Sie in Händen halten, verdankt seine Existenz in deutscher Sprache Jörg Heinemann. Wenn sich nicht er als Übersetzer und Sibel Türker als Lektorin bereit erklärt hätten, hätte ich mich niemals getraut, dieses Projekt zu beginnen. Ich danke Jörg aus tiefstem Herzen für die exzellente Übersetzung von Armenierinnen und Armenier in der Türkei. Es freut mich außerordentlich, dass er damit das Buch der deutschsprachigen Welt geschenkt hat. Genauso bin ich Sibel endlos dankbar, die die deutsche Übersetzung mit der türkischen Ausgabe Modern Türkiye'de Ermeniler Wort für Wort abgeglichen und mitsamt allen Updates lektoriert hat. Es ist ein Segen, mit ihnen beiden zusammenarbeiten zu können!

Aber ohne die finanzielle Unterstützung der Calouste Gulbenkian Foundation wäre diese Übersetzung nicht möglich gewesen. Daneben haben Harry und Hripsime Parsekian, Garbis und Laura Baydar, Ara und Aline Araz aus den USA sowie die deutsche Rosa-Luxemburg-Stiftung einen Teil der Kosten übernommen. Ich bin allen dankbar, die die Relevanz der Übersetzung und des Erscheinens dieses Buches in deutscher Sprache erkannt und dieses ermöglicht haben.

Vom ersten Tag an haben sich meine Editorin Sophie Wagenhofer beim Verlag De Gruyter sowie die Lektorin Katrin Mittmann umfassend um alles gekümmert. Sie waren und sind stets zuvorkommend und haben sich mit dem Buch tiefgehend auseinandergesetzt, das Manuskript kommentiert, meine Fragen beantwortet und sind immer bereit gewesen, wenn ich Hilfe gebraucht habe. Für ihren Einsatz und ihr Engagement bedanke ich mich herzlichst.

Meine langjährige Freundin Yeliz Soytemel hat es auf sich genommen, nach dem englischen Original und der türkischen Übersetzung auch die deutsche Ausgabe von Anfang bis Ende zu lesen und zu kommentieren. Ich bedanke mich bei ihr ebenfalls sehr herzlich für die Zeit, die aufgewendete Energie und Unterstützung.

Das schöne und sehr gelungene Cover ist Dörte Nielandt zu verdanken. Die Bilder hat uns Dr. Boris Adjemian von der Bibliothèque Nubar in Paris zur Verfügung gestellt. Auch hierfür vielen Dank!

München, 23. März 2021 
